\title{
Alimento e comida: sistema de abastecimento e consumo alimentar urbano
}

\author{
Aliment and food: System of provision and urban food consume
}

\author{
Newton Narciso Gomes Junior ${ }^{1}$ \\ Henrique Salles Pinto ${ }^{2}$ \\ Luisa Corrêa Leda ${ }^{3}$
}

\begin{abstract}
Resumo
A criação dos supermercados e a disseminação do alimento industrializado foram fatores determinantes no processo de urbanização e industrialização do Brasil no que tange as problemáticas associadas à alimentação da população. Simultaneamente, vivenciamos o desaparecimento dos sistemas tradicionais de abastecimento e a substituição do consumo de alimentos in natura e socialmente referenciados por uma gama de produtos industrializados e prontos para consumo que vêm contribuindo com o intenso avanço de problemas crônicos de saúde e da degradação de práticas alimentares tradicionais. Pretende-se aqui refletir sobre a questão urbana e o sistema de varejo de alimentos e sua conexão com a atual transição alimentar. Ao analisar o pequeno varejo e as transformações associadas à disseminação dos supermercados, argumenta-se sobre a importância da construção de um novo sistema de abastecimento alimentar urbano assentado sobre a estrutura de equipamentos tradicionais de varejo, sobre produtos da agricultura camponesa e voltado ao atendimento dos requisitos necessários para a plena fruição do Direito Humano à Alimentação. Conclui-se que, para isso, é fundamental considerar-se diversas ações, sendo algumas delas a revitalização do sistema atacadista representado pelas Centrais de Abastecimento, o incentivo e apoio à implantação de empresas associativas, o desenvolvimento de programas de revitalização de mercados municipais e feiras livres.
\end{abstract}

Palavras-chave: supermercados; alimentação saudável; sistema de abastecimento alimentar; pequeno varejo, hábitos alimentares.

\footnotetext{
Abstract

The creation of the supermarkets and the dissemination of industrial food were determinantes factors for the process of urbanization and industrialization and their concerns about feeding the population. Simultaneously, we experience the vanish of the traditional systems of food provision

${ }^{1}$ Economista. Professor dos programas de Pós-Graduação em Meio Ambiente e Desenvolvimento Rural e em Política Social, da Universidade de Brasília (UnB). E-mail: swnewtongomes@ gmail.com

${ }^{2}$ Mestre em Ciências Políticas pela Universidade de Brasília (UnB). E-mail: hsallep@ senado.gov.br

3 Mestranda pelo Programa de Pós-Graduação em Meio Ambiente e Desenvolvimento Rural (UnB). E-mail: luisa.ternera@gmail.com
}

Guaju, Matinhos, v.2, n.1, p. 61-76, jan./jun. 2016 
and the substitution of the consume of in natura and cultural embeded food for a range of industrialized and read-to-eat foods that contribute with the advance of chronical disease and the degradation of our traditional dietary habits. This work intend to reflect about the urban question and the retail food system and its connection with the current process of nutrition transition. Thinking about the small retail sector and the transformations associated with the dissemination of supermarkets, it argues about the importance of the construction of a new urban system os food provision settled upon the structure of the tradicional equipments of retail, the products of the peasant agriculture and oriented on attending the conditions for the fruition of the Human Right of Adequate Food. It concludes that is fundamental to consider many actions, like the revitalization of the public wholesale system, the incentive and support for the implementation of associative firms, the development of programs of revitalization of public food markets and fairs and the creation of a politc of Nourishment Education.

Keywords: supermakets; healthy nutrition; system of food provision; small food retail; dietary habits.

\section{Introdução}

Desde o momento em que a sociedade foi alertada para os riscos à saúde decorrentes da epidemia de obesidade decorrente de alterações nos padrões alimentares com dietas ricas em gorduras e que hoje se abate sobre mais da metade da população mundial, o debate sobre o que estamos comendo ganhou relevância na agenda de preocupações seja de pesquisadores e formuladores de políticas públicas sobre o tema seja do cidadão.

Convivemos e acostumamo-nos a naturalizar composições alimentares que não passam de imitação de comida, entregamo-nos ao consumo de coisas cuja composição exibe nomes tão impronunciáveis como indecifráveis. Adotamos, sem tempo para pensar, a refeição rápida, o ato de comer em pé ou de tomar o alimento ao mesmo tempo quando executamos outras atividades. Nossas opções alimentares, mais e mais, fixam-se no consumo de um reduzido conjunto de espécies de alimentos que, uma vez industrializados, se convertem em milhares de itens de consumo enraizados em nossa insegurança alimentar crescente, induzida por uma inadequada dieta alimentar dominante.

$\mathrm{Na}$ esteira das discussões quanto ao que fazer para resgatar a ideia de alimentação saudável multiplicaram-se em todo o mundo experiências voltadas para um novo arranjo operacional para o sistema de abastecimento alimentar. Os temas abordados aqui estão diretamente relacionados com essas ideias. Para tanto, este artigo foi dividido em duas partes, afora esta Introdução. Em sua 
primeira parte, a intenção dos autores foi apresentar uma reflexão sobre a questão urbana e o sistema de varejo de alimentos hegemonizado pelo autosserviço, e suas conexões com a transição alimentar em curso enquanto a segunda parte desenvolve uma argumentação em defesa de um novo sistema de abastecimento alimentar urbano, que combine a praticidade do autosserviço com uma releitura dos equipamentos tradicionais de varejo de alimentos em geral, visando contribuir à consecução do Direito Humano à Alimentação Adequada.

\section{A comercialização de alimentos e a hegemonia do autosserviço}

O Brasil é um país de urbanização tardia. O início do processo que definiu o cenário atual remonta os anos 1950, e pode-se dizer que a urbanização brasileira se consolida a partir da segunda metade dos anos 1960, nas asas do modelo de desenvolvimento econômico implementado pela ditadura militar que governou o país entre 1964 e 1985.

O modelo desenvolvimentista assumido a partir de 1968 contava com a forte presença do Estado na coordenação dos investimentos mais importantes, notadamente aqueles destinados a melhorar a infraestrutura, identificada como fator decisivo para o desenvolvimento do país. Nesse contexto, o abastecimento alimentar era identificado como um setor essencial para a consecução dos objetivos do modelo econômico implantado (LINHARES E SILVA, 1979; WEGNER, 2011). A ideia era assegurar uma modernização no segmento de comercialização dos alimentos de modo a reduzir as restrições de acesso, fossem elas por ineficiências da oferta, fossem pela inadequação da rede capilar de varejo. A instabilidade de preços, via de regra, era atribuída a essas ineficiências, como também ao peso das intermediações desnecessárias - atravessamento da comercialização -, implicando elevação artificial dos preços. Para os planejadores e gestores políticos daquele momento, um sistema de abastecimento eficiente era um pré-requisito para a redução dos gastos com alimentação, refletindo imediatamente no custo de reprodução da força de trabalho e assim, diminuindo a pressão social e política da classe trabalhadora sobre o patronato e o governo.

Como instrumento para a construção desse cenário, em 1969, o governo federal cria o Grupo Executivo de Modernização do Abastecimento (GEMAB) com a missão de coordenar a 
implantação do Sistema Nacional de Centrais de Abastecimento (SINAC), tendo como foco a instalação de centrais de abastecimento (BELIK, 2001).

De acordo com o entendimento dos idealizadores do SINAC, o problema do estrangulamento da circulação e comercialização da produção de alimentos, particularmente frutas, legumes, verduras, frangos, ovos e pescado, seria resolvido com a operação de espaços de comercialização, onde a reunião de seus agentes - produtores e atacadistas - por si, graças à "mágica da livre concorrência", reduziria custos e por conseguinte, os preços desses produtos para o consumidor, barateando os gastos com alimentação. Naquele momento, consolidava-se o modelo representativo dessa nova forma de comercialização de alimentos, o supermercado, presente na cena do abastecimento brasileiro desde os anos 1950 (MOURÃO \& MAGALHÃES, 2009; WEGNER, 2011).

A presença do supermercado no cotidiano da vida brasileira, entretanto, demandou importantes esforços no sentido de romper com práticas e modelos de comercialização varejistas arraigadas e protegidas pela legislação em vigor à época e os próprios hábitos de compra dos brasileiros.

Analisando a evolução do varejo e as mudanças no mercado brasileiro, Belik (2001) destaca que até os anos 1950 a legislação que regia a operação do varejo no Brasil definia que os equipamentos voltados para o ramo da alimentação deveriam funcionar de domingo a domingo até, pelo menos, às 8 horas da noite. Tal determinação não implicaria maiores custos para empresa posto serem os proprietários e seus parentes aqueles que estariam no atendimento e, acresça-se, observa Belik (2001), que os finais de semana eram responsáveis por mais da metade do movimento desses equipamentos.

Nada é mais representativo das mudanças que ocorrem no perfil do consumo que a introdução dos supermercados no Brasil. Até o fim dos anos 50, a legislação que regulamentava o comércio de alimentos era extremamente antiquada e obsoleta em praticamente todas as cidades do Brasil. As lojas de secos \& molhados e padarias eram obrigadas a trabalhar aos sábados e domingos até as $20 \mathrm{hs}$ e os primeiros supermercados também deveriam se enquadrar nesta categoria. Como normalmente o varejo de alimentos era administrado pela própria família era natural, como exposto, que funcionasse aos finais de semana, responsável por $50 \%$ do movimento destas lojas. Tais 
impedimentos faziam com que a instalação de estabelecimentos comerciais do varejo de alimentos, fora dos moldes convencionais, fosse custosa.

Outra questão institucional importante era a carga tributária imposta à venda de alimentos. Até 1966, era vigente no Brasil o sistema de impostos "em cascata" do IVC - Imposto sobre Vendas e Consignações. O IVC era aplicado em todas as fases de produção e distribuição de uma determinada mercadoria. A alíquota do IVC era, em princípio, reduzida elevando-se à medida que os Estados demandavam mais recursos. Como o supermercado trabalhava com uma estrutura profissional, na prática, não era possível praticar a sonegação como nas pequenas empresas. Isto levava a custos mais elevados de operação.

No imaginário brasileiro de fins dos anos 1960 e início dos 1970, o supermercado apresentava-se, todavia, como um espaço de modernidade. A diversidade da oferta, incluindo produtos para além dos alimentos in natura, como produtos alimentares funcionais e práticos, itens de higiene e limpeza, utilidades domésticas, padaria, açougue e mercearia, tudo em um mesmo local, com horário de funcionamento estendido até às 22 horas e preços significativamente mais baratos na comparação com os praticados pela rede tradicional de varejo, fez do autosserviço mais do que uma opção de compra: converteu-o em um programa familiar mensal, a exemplo dos shopping centers nos dias de hoje.

Com o estabelecimento do autosserviço das grandes redes de supermercados entre fins dos anos 1970 e 1980, rompeu-se, em tese, o paradoxo clássico do abastecimento, segundo o qual os pobres comeriam pior do que os ricos e pagariam mais por isso. Os supermercados abocanharam por intermédio da expansão das lojas para zonas-polo nas periferias, ou seja, locais identificados como centros comerciais regionais de um conglomerado de bairros periféricos - a clientela que se abastecia originalmente nas feiras livres, empórios e armazéns, açougues e padarias próximos de sua moradia.

Essa migração para os novos equipamentos de consumo, possivelmente, representou uma redução importante nos gastos com alimentação e produtos de higiene e limpeza. A escala de compras e a alta rotação das mercadorias acessível aos recursos econômicos dos supermercados, a política de pagamento de seus fornecedores a prazo, as estratégias de preços a partir de uma forte combinação de produtos e o fato de realizarem vendas somente a vista, com pagamento imediato por parte dos consumidores, entre outros fatores, explicam os preços baixos praticados pelo 
segmento. Enquanto esse modelo se afirma junto ao consumidor, o comércio tradicional, impossibilitado dessa escala de ação, paga fornecedores a vista ou em curtíssimo prazo, e tem parte de suas vendas vinculadas ao crédito concedido ao consumidor.

O esgotamento da capacidade operacional do antigo comércio varejista e a melhoria das condições de acesso aos alimentos e demais itens da cesta de consumo, possibilitada pela expansão da rede supermercadista, envolve alguns contenciosos. Um deles diz respeito à qualidade dos alimentos acessíveis. O comércio varejista convencional, no início da era dos supermercados, ainda operava com uma combinação de produtos alimentícios onde predominava a oferta de alimentos in natura combinados com poucos itens industrializados, principalmente enlatados e empacotados, há muito tempo incorporados ao cotidiano alimentar brasileiro.

Essa oferta, disponível nos equipamentos tradicionais - feiras livres, empórios e armazéns, mercearias, açougues e padarias -, expressava uma relação direta com um padrão alimentar assentado no consumo de comida socialmente referenciado nos padrões históricos e culturais da gastronomia brasileira. As práticas relacionadas às compras nesse circuito convencional implicavam o desenvolvimento e a permanência de laços de confiança entre comerciantes e clientes, de tal modo que, em última instância, o proprietário do estabelecimento era o fiador da qualidade e segurança dos produtos que vendia.

Se no circuito do varejo convencional, a qualidade, sanidade e segurança dos produtos estavam hipotecadas ao proprietário vendedor - fosse ele feirante, açougueiro, padeiro ou dono de empório, armazém ou mercearia -, nos supermercados, essa responsabilidade ou confiança se encontraria na bandeira da rede. Aqui, não há uma figura humana que se responsabilize diretamente pelo que está sendo vendido, e a qualidade da alimentação sofre mudanças de significado: tanto mais processado, congelado, pré-pronto um produto, mais seguro se parece à ideia-padrão de que o processamento industrial esteriliza riscos.

Em 'Fighting Malnutrition', Musgrove (MUSGROVE, 1989) chama a atenção para um aspecto interessante da migração das compras de alimentos para o espaço dos supermercados. À noção de modernidade que o autosserviço incorporou, seguiram-se modismos alimentares representados pelo consumo acentuado de produtos a requerer pouco tempo de preparo, embora isso implique o ultra-processamento e suas inevitáveis adições de componentes artificiais destinados a realçar sabores, intensificar cores e aromas e, principalmente, estender a validade desses alimentos. 
Inicialmente, o novo padrão foi associado ao consumo das classes de maior renda, para logo atingir a maioria da população. Contudo, prevalecia uma assimetria bastante evidente entre os preços dos alimentos ultra - processados e a renda disponível para gastos com alimentação por amplos setores assalariados e de baixa renda.

Em tempo de forte inflação, salários arrochados e renda instável, a opção pelos supermercados significava a possibilidade de comprar mais produtos essenciais com menos dinheiro. Entretanto, pela mesma porta de acesso a produtos mais baratos, encontravam-se também as novidades alimentares que frequentavam o imaginário social dos menos favorecidos economicamente, desejosos de uma vida igual ou semelhante à dos ricos que gostariam de ser. Daí à mudança das preferências de compras em direção a esses desejos de consumo decorreu um curto espaço de tempo. A ‘comida que não é comida' (FLANDRIN \& MONTANARI, 1998) chegou à mesa de todos, mesmo que significasse reduzir as quantidades de alguns gêneros básicos para dar lugar a outros que satisfizessem muito mais as necessidades da fantasia que as do estômago (MARX, 1979).

Durante a fase de transição do comércio e abastecimento de alimentos, o problema da insegurança alimentar no Brasil, todavia, era predominantemente definido pela assimetria entre as necessidades alimentares e a insuficiência da ingestão de alimentos decorrente das restrições de renda. Eis porque os supermercados funcionaram tanto como uma oportunidade para melhorar o acesso aos alimentos, mediante práticas de preços competitivos com os do mercado convencional. Sem esquecer sua importância progressiva para a redução nos custos da reprodução da mão de obra. Estudiosos e profissionais envolvidos coincidem sobre a seguinte questão do abastecimento alimentar urbano brasileiro: os anos 1980 foram marcados pela (i) consolidação da liderança do autosserviço como equipamento de varejo de alimentos e (ii) desidratação do sistema público de abastecimento alimentar, até então sustentado pelas centrais de abastecimento, e da rede capilar de varejo convencional, esta representada pelos mercados municipais, feiras livres, empórios e armazéns, mercearias, açougues e padarias, e assemelhados (BELIK, 2001).

O domínio dos supermercados na distribuição de alimentos é, indiscutivelmente, um fator inibidor da concorrência entre o segmento varejista. De acordo com dados publicados pela Associação Brasileira de Supermercados (ABRAS), o autosserviço alimentar, por dez anos seguidos, apresentou expansão real de suas vendas em torno de 5,5\% sobre o ano anterior. A revista 
SUPERHiPER, em sua edição de abril de 2014 (SUPERHiPER, 2014), revelou que o setor abrigava 83,9 mil lojas com 210,6 mil checkouts, área de venda total próxima dos 21,1 milhões de metros quadrados e um faturamento de mais de $\mathrm{R} \$ 272$ bilhões referentes à ampla gama de produtos ofertados nesses equipamentos. A mesma edição revela que as vendas de alimentos no varejo têm nos supermercados seus principais atores, responsáveis por mais de $80 \%$ do total movimentado pelo setor. Esse quadro de liderança dos supermercados, independentemente de seu tamanho, de pertencerem ou não às grandes redes de varejo, é apoiado pelo avanço contínuo dos produtos alimentares industrializados na composição da cesta de compras dos brasileiros. De acordo com a Pesquisa de Orçamentos Familiares (POF, 2008/2009), se em 1980 a relação entre consumo de produtos in natura e produtos industrializados era quase pareada - os primeiros participavam com $44 \%$ no consumo alimentar, contra $56 \%$ de gêneros industrializados -, dez anos depois, essa relação alterou-se para $30 \%$ e $70 \%$, respectivamente, até cravar $15 \%$ de consumo de alimentos in natura contra $85 \%$ de alimentos industrializados em 2008.

No ranking da ABRAS (SUPERHiPER, 2014), as cinco grandes redes de supermercados, sendo as quatro primeiras estrangeiras: Pão de Açúcar, Carrefour, Walmart, Cenconsud (bandeira G Barbosa, com sede em Aracaju/SE), e Zafari do Rio Grande do Sul, dominavam 50\% do mercado. Entretanto, esse achado não implica que o oligopólio seja imbatível. De acordo com a $3^{\mathrm{a}}$ edição do Estudo Mercado de Vizinhança, realizado pelo instituto de pesquisa GfK do Brasil (NUNES FILHO, 2013), as pequenas lojas que operam com 1 a 2 checkouts seriam 65 mil em 2013. A mesma investigação aponta - 84\% constituiriam empresas familiares, operando há mais de 15 anos e tendo à frente dos negócios pessoas com idade entre 36 e 55 anos.

Em 2013, esse comércio expandiu suas vendas cerca de 1,2\% em relação ao ano anterior, enquanto para o mesmo período, o autosserviço cresceu 0,2\%. Sobre o mesmo estudo da GfK, Nunes Filho (2013) destaca que, nas lojas de vizinhança, a liderança das vendas é debitada ao setor de mercearia, que responde por $53 \%$ do faturamento. Desse montante, arroz, feijão e açúcar somam $33 \%$, e os demais itens, $67 \%$. Em seguida, bebidas respondem por $14 \%$ do faturamento, higiene e beleza, $11 \%$, refrigerados (que englobam açougue), $9 \%$, limpeza e frutas, legumes e verduras, $5 \%$, e bazar, 3\%. Quando os proprietários dos pequenos estabelecimentos de comércio de alimentos foram perguntados sobre o que definia sua política de compras, suas respostas mais frequentes foram os pedidos dos clientes aos proprietários, identificação de produtos inovadores, experiência própria do 
lojista e produtos que oferecem melhores margens de lucro, seguidas pela imitação das iniciativas de compra dos concorrentes e sugestões dos fornecedores.

Completando esse conjunto de informações, o Estudo Mercado de Vizinhança (NUNES FILHO, 2013) identificou que os canais de compras preferenciais para o setor de $\mathrm{FLV}^{4}$ são as compras diretas do produtor (35\% do total) e de distribuidores exclusivos (12\%), enquanto as compras por atacado respondem por $7 \%$. No setor de alimentos, compras de atacadistas representam $25 \%$, de multidistribuidores, $23 \%$, diretamente dos fabricantes, $22 \%$, e do distribuidor exclusivo, $19 \%$.

Não obstante a relevância do pequeno varejo de autosserviço, a parte principal do faturamento continua sob o comando das grandes redes. Os dados sobre a concentração do varejo no mundo, apurados pela assessoria de projetos e pesquisa Markestrat a partir de informações colhidas pelas empresas Tetrapack e Eurocamander, foram publicados no Caderno de Economia do jornal Folha de S. Paulo em sua edição de 27 de junho de 2014, pelo jornalista Mauro Zafalon (ZAFALON, 2014). De acordo com a publicação, as cinco maiores empresas varejistas de alimentos brasileiras respondiam, em 2013, por 53\% do faturamento do setor. Segundo a Oxfam (2013), em um cenário de 7 bilhões de consumidores e 1,5 bilhões de produtores de alimentos, cerca de 500 empresas controlam $70 \%$ de sua comercialização.

Essa tendência de expansão do domínio de poucos agentes no mercado de alimentação é um fenômeno mundial. Os dados obtidos pela pesquisa da Markestrat também revelam que na Alemanha, os cinco maiores varejistas de alimentos concentravam cerca de $66 \%$ das vendas do setor no ano 2000, saltando para 76\% em 2013; na França, em pouco mais de uma década, de 2000 a 2013, o peso do domínio dos cinco maiores varejistas cresceu de 70 para $73 \%$ do volume de vendas; finalmente (dados de 2013), os cinco maiores varejistas de alimentos do mundo concentram um faturamento anual de espantosos US\$983 bilhões, cifra maior que o orçamento de muitos países. No Brasil, as cinco maiores redes de autosserviço controlavam, em 2000, 41\% do mercado, subindo para 53\% em 2013. No ano de 2014, o autosserviço alimentar cresceu pelo décimo ano seguido, abrigando 83,9 mil lojas com 210,6 mil checkouts e um faturamento de mais de 272 bilhões, o que representa mais de $80 \%$ do total das vendas do setor varejista de alimentos (ABRAS/SUPERHIPER, 2014).

\footnotetext{
${ }^{4}$ FLV é a sigla que identifica nos supermercados o setor onde se concentram para venda as frutas, legumes e verduras.
} 
Tal nível de concentração estiola a força dos produtores rurais e da indústria de alimentos, particularmente (no caso das indústrias) das pequenas e médias plantas industriais, donas de marcas locais e regionais ou do segundo grupo de consumo (BELIK, 2001). Contudo em que pese os efeitos da crise econômica que sacode o mundo desde 2008, pequenas lojas, pequenas e médias indústrias de transformação e propriedades agrícolas camponesas têm respondido às pressões econômicas e mantido um ritmo de permanência. No caso de equipamentos varejistas, apesar da grande transformação sofrida pelo sistema de abastecimento (BELIK, 2001), vemos, no Brasil, a persistência de um grande número pequenos estabelecimentos de varejo de alimentos (NUNES FILHO, 2013).

Nesse contexto, a questão que se impõe é objetiva e simples: como, e por intermédio de que expedientes, têm os pequenos equipamentos varejistas, as pequenas e médias indústrias de transformação resistido ao domínio dos gigantes (NUNES FILHO, 2013)?

\section{Um novo arranjo para o abastecimento alimentar}

Os números do varejo tradicional de alimentos no Brasil guardam imprecisões de classificação, seja por excesso, seja por exclusão de ramos de produtos. Entretanto, se abstrairmos esses contenciosos e confrontarmos o total de equipamentos relacionados à comercialização de alimentos, o número de lojas de hipermercados e supermercados, aproxima-se dos $80 \%$ a participação de estabelecimentos classificados como comércio convencional.

A resistência - a despeito da relevância do peso do volume de vendas - do segmento supermercadista não constitui propriamente um mistério. A despeito do avanço e a facilitação dos instrumentos de crédito à disposição do consumidor - cartões de crédito -, independentemente da faixa de renda, dos vale-alimentação e, ao menos até recentemente, da relação favorável entre a renda e os preços dos alimentos em geral, os equipamentos convencionais sempre se mantiveram pela venda de conveniência ou pela concessão de crédito direto - as tradicionais cadernetas - que, em boa parte das ocasiões, asseguram prazos de pagamento para além dos 30 dias adotados pelas administradoras de cartões.

Guaju, Matinhos, v.2, n.1, p. 61-76, jan./jun. 2016 
Segundo a pesquisa da GfK do Brasil (NUNES FILHO, 2013), já citada, os equipamentos de varejo na modalidade de supermercado operando com 1 até 4 checkouts somam 65 mil lojas. A política de compras para o abastecimento dessas lojas obedece a uma lógica sem grandes sofisticações metodológicas. Assim como os proprietários dos pequenos estabelecimentos de comércio de alimentos, os comerciantes do pequeno autosserviço, quando perguntados sobre quais bases definiam suas compras, reportaram que, em primeiro lugar, guiavam-se pelo que os clientes regulares lhes pediam, seguindo-se pela compra de produtos inovadores, sua própria experiência e opção por produtos com melhor margem de venda. Ainda sobre a lógica de suas compras, esses comerciantes revelaram que sua decisão poderia ser influenciada tanto pela diversidade da oferta dos concorrentes quanto pela sugestão dos fornecedores.

A Figura 1 ilustra a participação na composição das vendas do pequeno autosserviço por ramos de produtos, cuja liderança cabe ao setor de mercearia, no qual arroz, feijão e açúcar respondem por $33 \%$. O peso dos refrigerados é de $9 \%$, metade desse total representado pelas carnes segundo o estudo. Bebidas e higiene-beleza contribuem com 14\% e 11\%, respectivamente, enquanto limpeza e FLV respondem por apenas $5 \%$ das vendas.

\section{Participação por setor no volume de vendas}

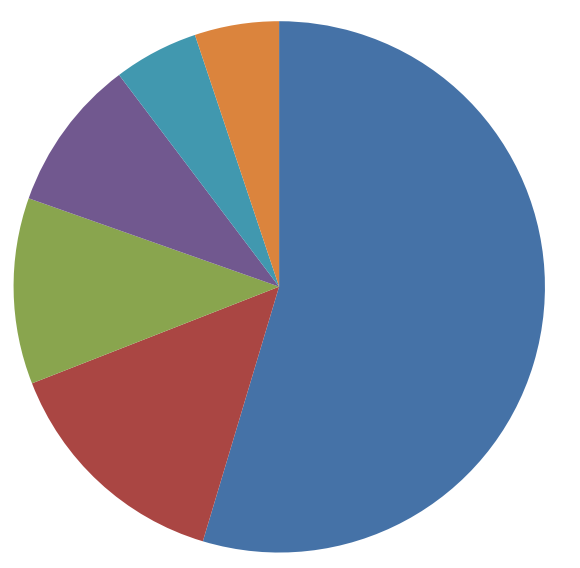

- Mercearia

Bebidas

Hig. Beleza

Refrig.

- Limpeza

aLV

FIGURA 1 - PARTICIPAÇÃO NA COMPOSIÇÃO DAS VENDAS POR RAMOS DE PRODUTOS, NO PEQUENO AUTOSSERVIÇO

FONTE: Estudo Mercado de Vizinhança/GfK, 2013 
A mesma pesquisa da GfK destaca que, nesses pequenos estabelecimentos de autosserviço, as grandes marcas do varejo respondem por apenas 18,6\% dos gastos na loja e que o valor médio do ticket do setor seria de $\mathrm{R} \$ 23,63$ em valores de 2013. Entretanto, é no que toca à fidelidade do cliente que o segmento do pequeno varejo moderno de alimentos se destaca: a pesquisa revelou que, enquanto o nível de fidelidade do consumidor aos supermercados e hipermercados é de $16 \%$ e $6 \%$ respectivamente, os pequenos mercados com 1 a 4 checkouts contam com a lealdade de $48 \%$ dos usuários.

Viu-se, nas seções iniciais desse ensaio, que o comportamento do consumidor é fortemente influenciado pelas restrições de mobilidade urbana, responsáveis por uma redução significativa no tempo disponível do cidadão para outras atividades cotidianas que não o deslocamento e o trabalho. Essa realidade induz as decisões do indivíduo quanto ao tipo de produtos alimentares adquirir, assim como seu comportamento diante do que comer no momento das refeições.

Estudos sobre o comportamento do consumidor têm apontado que, em alguma medida, os preços dos produtos já não são um obstáculo insuperável na hora de escolher o local onde comprar. As compras feitas no intervalo do trabalho ou no trajeto de volta a casa combinam rapidez e praticidade, associadas a pequenas áreas de venda capazes de oferecer uma pauta de produtos que atenda as necessidades do consumidor, sem maiores exigências quanto ao contexto ou grau de sofisticação do local.

Compras em pequenas quantidades determinam uma frequência maior de visitas do consumidor às lojas. Em contrapartida, a localização do comércio perto do domicílio ou do local de trabalho, ou de fácil acesso ao transporte público, acaba por compensar o tempo dispendido em compras maiores, disponibilizadas pelos grandes supermercados. Diferenças nos preços praticados entre um e outro equipamento - diga-se, nem tão relevantes como já foram noutros tempos acabam por exercer pouca influência na decisão de onde comprar.

O processo dinâmico desse cenário que, segundo estudiosos e pesquisadores, fortalece a crescente convicção de uma tendência à expansão e fortalecimento, nas grandes e médias cidades, da pequena loja em detrimento das grandes plantas comerciais, parece ter sido captado pelas grandes redes de supermercados. Estas, em diversas cidades brasileiras, já implantaram lojas com 2 
a 4 checkouts e uma pauta de produtos e serviços mais enxuta e adequada ao perfil de seus consumidores preferenciais.

\section{Conclusão}

Não seria temerário falar na existência, no Brasil de hoje, de um sistema varejista urbano de alimentos no qual pequenos supermercados familiares convivem com uma rede capilar de equipamentos tradicionais, representados por feiras livres, mercados municipais, mercearias, quitandas, padarias e açougues, entre outros.

A partir das questões ponderadas neste ensaio, um breve delineamento do que seria um novo sistema de abastecimento alimentar, comprometido com a garantia da segurança alimentar e nutricional e voltado ao atendimento dos requisitos necessários para a plena fruição do Direito Humano à Alimentação, deveria considerar as seguintes ações:

a) Revitalização do sistema atacadista representado pelas Centrais de Abastecimento, de sorte a (i) ampliar sua participação na composição da oferta de alimentos tradicionais e (ii) regular e evitar a formação dos oligopólios que hoje dominam a comercialização de alimentos por essas mesmas centrais.

b) Criação de um Sistema Nacional de Informações de Mercado sob a responsabilidade da Conab, que se valha de todos os meios sinestésicos disponíveis para a difusão de preços e orientação a produtores, vendedores, intermediários e compradores.

c) Incentivo e apoio à implantação de empresas associativas, instaladas à jusante da produção, em assentamentos de reforma agrária e cinturões verdes de agricultura camponesa, de maneira a eliminar parte dos riscos representados pelos terminais de atacado ou plataformas a que se submetem esses agricultores, fortalecendo a comercialização de seus produtos em cadeias curtas e aproximando-os do varejo de alimentos, restaurantes e bares, mercado institucional, etc.

d) Estímulo a programas de industrialização de alimentos de alcance local e regional, pautados no processamento essencial, especialmente de laticínios, leite pasteurizado, conservas e compotas, aves e suínos.

Guaju, Matinhos, v.2, n.1, p. 61-76, jan./jun. 2016 
e) Recuperação dos princípios norteadores de estudos das cadeias voluntárias e de modernização do pequeno e médio equipamento varejista de alimentos, desenvolvidos em fins dos anos 1970 (1977) como forma de agregar competitividade e fortalecer o sistema varejista de alimentos representado por lojas de autosserviço com 1 a 4 checkouts e a rede capilar de varejo convencional, oferecendo-lhes melhores condições para se abastecerem de produtos locais e regionais.

f) Desenvolvimento de programas de revitalização de mercados municipais e feiras livres, adaptados às novas exigências da urbanização, reduzindo seu impacto sobre o espaço e a mobilidade cidadã. Tal iniciativa implica recuperar os arranjos de compactação e confinamento de feiras livres, desenvolvidos nos anos 1980 em grandes centros urbanos, alterar sua operação para o turno verspertino, etc.

g) Incentivo à criação de associações de consumidores, capacitando-os para o consumo de alimentos saudáveis, práticas alimentares tradicionais e comprometimento com produtos alimentícios produzidos na localidade ou região de seu domicílio.

h) Desenvolvimento de programas de recuperação de restaurantes populares - não confundir com o modelo de parceria público-privada dos restaurantes a $\mathrm{R} \$ 1,00$-, de modo a facilitar o acesso ao crédito para compra de equipamentos e realização de adaptações físicas nas cozinhas e áreas de atendimento. Além disso, estímulo à volta ao hábito cotidiano da comida servida nas modalidades de 'Prato Feito' e 'Comercial', ou 'Prato do Dia' e 'Minutas', de forma a resgatar hábitos alimentares tradicionais sacrificados na esteira dos restaurantes self-service, estes pautados no pagamento dos alimentos consumidos pelo peso, dos lanches rápidos em substituição às refeições, e outras formas de alimentação inadequadas à saúde. Os restaurantes de tipo self-service, assim como os supermercados, se pautam na oferta descomedida de produtos e instauram uma espécie "cacofonia alimentar", contribuindo para a desconstrução das identidades associadas às práticas alimentares (FISCHLER, 1995).

i) O estímulo à gestão compartilhada entre todos os participantes da cadeia de produção de alimentos (indústria de insumos e equipamentos, agricultores, indústria de processamento, distribuidores, representantes do Estado e consumidores), com o objetivo de mitigar o desperdício desde o início da produção. 
Os pontos aqui apresentados não constituem, sequer pretendem em si mesmos, apresentarem-se como diretrizes do que se poderia intitular uma nova Política Nacional de Abastecimento Alimentar. A intenção dos autores, ao concluir este ensaio, é tão somente indicar caminhos já trilhados - em um passado não muito distante -, e que poderiam ser definidos e implementados via políticas federais, estaduais e municipais.

O propósito e a ação pela construção de uma política de abastecimento com o objetivo de incentivar a alimentação saudável, a produção segura de alimentos e sua comercialização adequada, segura e justa, deve contemplar um esforço nacional em que os três níveis de governo, federal, estadual e municipal, estejam envolvidos na medida de sua competência, em igual intensidade. A consecução do DHAA no Brasil é um desafio. E uma tarefa a cumprir, de responsabilidade do governo e da sociedade.

\section{Referências}

BELIK, Walter. (2001). Muito além da porteira: mudanças nas formas de coordenação da cadeia agroalimentar no Brasil. Campinas: UNICAMP, 2001.

BRASIL. Pesquisa de Orçamento Familiar - POF 2008/2009.

BRASIL. Pesquisa Nacional por Amostra de Domicílios - PNAD 2009.

DOYAL, L.; GOUGH, I. A theory of human needs. London: Macmillan, 2001.

FISCHLER, Claude. El (h) omnívoro. El gusto, la cocina y el cuerpo. Barcelona: Anagrama, 1995, $424 \mathrm{p}$.

FLANDRIN, J. L.; MONTANARI, M. História da Alimentação. São Paulo: Estação Liberdade, 1998.

ZAFALON, M. Concentração do varejo reduz força de produtores de alimentos nas vendas. Folha de S. Paulo, São Paulo, 27 jun 2014. Caderno de Economia.

GOMES JR, N. N. Aspectos da Insegurança Alimentar no Brasil de hoje: notas para discussão. Argumentum: revista do Programa de Pós-Graduação em Política Social da Universidade Federal do Espírito Santo, Vitória, v. 6, n. 2, 2014. 
GOMES JR, N. N. Segurança Alimentar e Nutricional e Necessidades Humanas Básicas, Ed Perseu Abramo, São Paulo, 2015.

LINHARES, M. Y. L.; SILVA, F. C. T. História política do abastecimento: 1918-1974. Brasília: Binagri, 1979.

MARX, K. O Capital, Livro I. São Paulo: Boitempo, 2014.

MOURÃO, I. A.; MAGAlHÃES, J.S.B. Breve história do Mercado de Hortigranjeiros no Brasil. IBAM, 2010.

MUSGROVE, P. Figthing Malnutrition: in evaluation of Brazilian food and nutrition programs. Washington: World Bank Discussion Papers, 1989.

NUNES FILHO, R. O grande mercado das pequenas empresas. GfK do Brasil. Estudo Mercados de Vizinhança. SUPERHiPER: revista da Associação Brasileira de Supermercados (ABRAS), São Paulo, ano 39, número 444, jun 2013, p 52-69.

OXFAM, 2013. Por trás das marcas: Justiça alimentar e as "10 Grandes" empresas de alimentos e bebidas. Disponível em: <https://www.oxfam.org/sites/www.oxfam.org/files/file_attachments/bp166-behind-the-brands260213-pt_2.pdf)>.

PEREIRA, P. A. P. Necessidades Humanas. São Paulo: Cortez, 2000.

POLLAN, M. Regras da Comida. Rio de Janeiro: Intrínseca, 2013. Edição digital.

SUPERHiPER: revista da Associação Brasileira de Supermercados (ABRAS), São Paulo, ano 40, número 454, abr 2014, p 40-169.

SCHLINDWEIN, M. M.; KASSOUF, A. L. Mudanças no padrão de consumo de alimentos tempointensivos e de alimentos poupadores de tempo por região do Brasil. In: SILVEIRA F. G. et al. Gasto e consumo das famílias brasileiras contemporâneas, v. 2. Brasília: IPEA, 2007.

WEGNER, R. Configuração da Política de Segurança Alimentar e Nutricional no Brasil: O Estado e o Mercado no Abastecimento Alimentar. 2011. Dissertação (Mestrado em Desenvolvimento Econômico) - Instituto de Economia, Universidade Estadual de Campinas, 2011.

Artigo recebido em 02/05/2016. Aceito para publicação em 19/07/2016.

Guaju, Matinhos, v.2, n.1, p. 61-76, jan./jun. 2016 